\title{
MULTIMODALIDADE E LETRAMENTO VISUAL: UM ESTUDO PILOTO DE ATIVIDADES DE LEITURA DISPONÍVEIS EM SÍTIO ELETRÔNICO
}

\section{MULTIMODALITY AND VISUAL LITERACY: A PILOT STUDY THAT INVESTIGATES WEBSITES READING ACTIVITIES}

\author{
Vânia Soares Barbosa* ${ }^{1}$ \\ Antonia Dilamar Araújo* $*^{2}$
}

RESUMO: Este artigo apresenta um estudo piloto que investiga atividades de leitura em língua inglesa disponíveis em sítio eletrônico. Com foco na análise da relação texto e imagem nestas atividades, o estudo objetiva diagnosticar a possível correlação, ou a falta desta, entre a multimodalidade nos textos apresentados e a exploração desta para fins didáticos através dos enunciados e conteúdos das questões propostas, e, assim, indicar a promoção do letramento visual dos leitores/usuários daquelas atividades.

PALAVRAS-CHAVES: Leitura. Multimodalidade. Letramento Visual.

ABSTRACT: This article presents a pilot study that investigates online websites reading activities in English, with a focus on the analysis of text-image relation in these activities. The study aims to diagnose the possible correlation, or lack of it, between multimodality in the texts presented and the exploitation of it for teaching purposes, by considering the statements and contents of the questions posed, and thus indicate the promotion of readers/users visual literacy of those activities.

KEYWORDS: Reading. Multimodality. Visual Literacy.

\footnotetext{
${ }^{1}$ Universidade Federal do Piaui, Teresina, professora Assistente do Departamento de Letras, doutoranda em Linguística Aplicada na Universidade Estadual do Ceará, E-mail: vaniasb@uol.com.br;

${ }^{2}$ Universidade Estadual do Ceará, Fortaleza, professora Titular do Departamento de Letras e do Programa de Pós-Graduação em Linguística Aplicada, doutora em Letras, E-mail: dilamar@gmail.com.
} 


\section{MULTIMODALIDADE E LETRAMENTO VISUAL: UM ESTUDO PILOTO DE ATIVIDADES DE LEITURA DISPONÍVEIS EM SÍTIO ELETRÔNICO}

\section{INTRODUÇÃO}

Diante dos avanços nas Tecnologias de Comunicação e Informação (TIC), a elaboração e produção de materiais didáticos, sejam eles impressos ou digitais, tem proporcionado transformações em seus designs gráficos, tornando-os cada vez mais multimodais, como afirmam Martinec \& Salway (2005, p.337): “[...] devido ao ritmo implacável da evolução das tecnologias de comunicação e informação, texto e imagens estão cada vez mais integrados criando textos multimodais". "Estas transformações são resultantes, entre outras coisas, das facilidades que aqueles avanços proporcionam na inserção e manipulação de diferentes modos e recursos semióticos, como, por exemplo, o texto verbal (e nestes incluem-se, também, a tipografia - cores, tipos, estilo e tamanho da fonte - e a própria organização textual), imagens (estática e em movimento) e sons. A visualização nesses materiais tem sido atestada, ainda, por autores da Semiótica Social, como Unsworth at all (2004) e Bezemer \& Kress (2009), sendo que estes últimos destacam a necessidade de atentar para o design multimodal de materiais mais que para um modo e/ou recurso semiótico isoladamente ${ }^{4}$.

Entretanto, se, por um lado, estamos diante uma inquestionável e crescente visualização de materiais didáticos, especialmente aqueles disponíveis em meio digital, por outro lado, o mesmo não pode ser dito a respeito do acompanhamento daqueles avanços pelas práticas pedagógicas que não parecem estar "adequadamente acomodadas aos textos multimodais" 5 " (UNSWORTH, 2009, p.398), levando-nos a considerar a

\footnotetext{
${ }^{3}$ Tradução nossa para: "[...] due to the relentless pace of developments in information and technology, text and images are increasingly coming together creating multimodal texts." Doravante todas as citações em língua estrangeira serão traduzidas sob nossa responsabilidade.

4 “[...] one needs to look at the multimodal design of textbooks rather than at image or any other mode in isolation." (p. 249)

${ }^{5}$ The first concerns renovating current pedagogic practices that do not adequately accommodate
} 
possibilidade de que nestes materiais a relação entre multimodalidade e letramento visual não seja convergente, ou ainda, mais especificadamente, entre a variedade de recursos semióticos disponibilizados e o que é esperado de seus usuários para a realização das atividades propostas. Em outras palavras, a convergência à qual nos referimos estaria próxima ao que Unsworth (id. ibidem) chama de "uma metalinguagem comum que explique o processo de produção de sentido nas relações imagem-texto a fim de facilitar o ensino mais sistemático, aprendizagem avançada, e abordagens de avaliação" (UNSWORTH, 2009, p.398), ou que, simplesmente, promova o letramento visual através dos enunciados de suas questões incentivando o leitor de composições multimodais a integrar todos os recursos na produção de sentido e não ficar restrito às informações verbais.

Assim, este trabalho analisa atividades de leitura em língua inglesa disponíveis em sítio eletrônico com o objetivo de observar a organização do design gráfico, em sua relação texto e imagem, e diagnosticar a possível contribuição desta para ampliar o letramento visual de seus usuários, considerando os enunciados e as questões propostas para a realização daquelas atividades. Para tanto, selecionamos cinco atividades de leitura da série Beyond the Postcard, disponível no portal www.bbc.co.uk, de um total de doze, e submetemos seus textos a uma análise descritiva, considerando relações entre texto e imagem, para em seguida contrapor os resultados desta análise aos enunciados e questões mencionados. Para esta análise, tomamos como principais bases teóricas a Gramática do Design Visual (GDV) de Kress e Van Leeweun (2006) que explica o valor de informação na metafunção composicional, das relações de status entre textoimagem propostas por Martinec e Salway (2005), além de trabalhos que analisam materiais didáticos desenvolvidos por Bezemer \& Kress (2009) e Unsworth et al (2004).

\section{MULTIMODALIDADE: TEXTO E IMAGEM EM DISCUSSÃO}

Os avanços tecnológicos têm facilitado o acesso e a circulação de informação, abrindo caminhos e quebrando barreiras à comunicação. Um dos efeitos dessa maior rapidez na comunicação e na circulação de informação é um crescente papel da imagem em diferentes contextos dos relacionamentos humanos. ${ }^{6}$ Dessa forma, a imagem, que por muito tempo vinha sendo relegada ao papel de suporte ao texto escrito, embora sempre tenha estado presente em toda forma de comunicação, reassume uma importância nos mais variados contextos da sociedade contemporânea pelo impacto e influência que exerce sobre as pessoas como também pelo significado que veiculam.

Neste contexto social, partindo das ideias do britânico M. A. K. Halliday, teóricos, tais como Kress e Van Leeuwen (2006), Mayer (2009), Machin (2007), entre outros, ressaltam a comunicação como um evento multimodal que agrega e integra diversos modos semióticos (verbal e não verbal) na criação do texto e na produção do sentido, respectivamente, de forma mútua e complementar, em um processo indiscutivelmente cultural e social. De acordo com Van Leeuwen (2011, p.668), o termo Multimodalidade se refere, portanto, ao "uso integrado de diferentes recursos comunicativos, tais como a linguagem, imagem, sons e música em textos multimodais e eventos comunicativos". 7

\footnotetext{
multimodal texts.

${ }^{6}$ Nas mensagens transmitidas através da telefonia móvel, nos emoticons utilizados em salas de bate-papo, entre tantos outros.

7 “integrated use of different communicative resources, such as language, image, sound and music in
} 
Um dos caminhos para esse uso integrado dos diferentes recursos semióticos foi desenvolvido por Kress e Van Leeuwen (2006) com a proposta da Gramática do Design Visual que parte da Gramática Sistêmico Funcional (GSF) de Halliday para explicar e descrever a organização estrutural das informações visuais presentes nos textos, e evidenciar o potencial discursivo da imagem na produção e reprodução do sentido. Desta premissa, os autores mostram que assim como na linguagem verbal, é possível observar a regularidade das metafunções da linguagem (ideacional, interpessoal e textual) no código visual, e propõem três estruturas de representações básicas para cada metafunção: a representacional, a interacional e a composicional, respectivamente.

Segundo os autores, a metafunção representacional traduz a relação entre os participantes através de vetores que indicam as ações desses participantes na imagem ou de uma classificação que os coloca como subordinados a uma categoria superior (ALMEIDA, 2008, p.13). O elo entre o produtor da imagem e o leitor, de aproximação ou de afastamento, pode ser identificado na análise da metafunção interativa. Ainda por meio de vetores, esta interação é apontada segundo o possível contato entre os atores (produtor e leitor), o distanciamento social, a perspectiva em que os participantes são mostrados e a modalidade na qual as coisas são representadas e que pode ser da mais próxima do real a mais irreal. Finalmente, a integração dos elementos visuais (representacionais e interativos) de uma imagem é realizada na metafunção composicional para indicar o valor de informação de cada elemento, estabelecido de acordo com a posição que ocupa na imagem; a saliência (planos, tamanhos, contrastes de cor, etc.) que faz com que a atenção do espectador seja atraída para determinado elemento; e a estruturação (linhas que conectam ou desconectam os elementos da imagem) que pode indicar se estes elementos compõem um mesmo sentido (id. ibidem).

Para a análise que apresentamos, a relação texto e imagem será investigada em sua realização da metafunção composicional quanto a categoria valor de informação que, nas palavras dos autores da gramática significa que "a localização dos elementos (dos participantes e dos sintagmas que conecta uns aos outros e ao espectador) lhe atribui valores de informação específicos em relação aos outros ${ }^{8}$ " (KRESS \& VAN LEEUWEN, 2006, p.176). Elementos posicionados à esquerda são apresentados como dado e, portanto, trazem informações que se supõem já tenham sido compartilhadas com o leitor, enquanto o posicionamento dos elementos à direita é dito como novo e apresentam informações novas para as quais o leitor deve dar atenção especial (id. Ibidem, p.180). Quando é possível distinguir elementos posicionados na parte superior e inferior da imagem, uma relação entre ideal e real é estabelecida, respectivamente, para indicar uma contraposição em relação à informação idealizada, generalizada e a informação concreta, verdadeira. Uma terceira combinação de elementos pode ser observada quando dado-novo ou ideal-real se combinam com o elemento central da imagem (centro-margem) formando um bloco de informações que os autores chamam de trípticos e no qual o elemento central exerce o papel de mediador entre os demais elementos. Estas são algumas sub-categorias que Kress e Van Leeuwen (2006) estabelecem para analisar as informações não verbais semelhantes àquelas aplicadas à análise da linguagem verbal, ressaltando o papel da imagem nos eventos comunicativos.

multimodal texts and communicative events,"

${ }^{8}$ In other words, the placement of the elements (of the participants and of the syntagms that connect them to each other and to the viewer) endows them with specific information values relative to each other. 
Outro caminho para a análise da multimodalidade é observar a relação textoimagem. Um dos primeiros trabalhos a discutir essa relação foi elaborado por Barthes (1977) que, numa perspectiva da semiótica estruturalista, apresentou três possibilidades de interação: ancoragem - quando o texto apoia a imagem; ilustração - a imagem apoia o texto; e 'relay' - na qual há uma relação de complementaridade entre texto e imagem e que influenciou os sistemicistas a pensarem na integração texto-imagem. A partir de Barthes (1977) e de categorias, tais como elaboração, extensão e aprimoramento, da Gramática Sistêmico-Funcional (GSF) de Halliday, teóricos como Van Leeuwen (1991), Kress \& Van Leeuwen (2006), Unsworth (2004), Martinec \& Salway (2005), têm investigado e estabelecido diferentes possibilidades de interação texto e imagem, podendo as categorias da GSF serem aplicadas para identificar a natureza facilitadora que aquela integração possa trazer para a aprendizagem.

Segundo o sistema proposto por Martinec \& Salway (2005, p.343), assim como nas orações verbais, a relação semântica texto e imagem pode ser analisada especialmente sob dois aspectos: status, quando imagem e texto estabelecem uma relação de independência, complementaridade ou subordinação; e realização lógicosemântica ${ }^{9}$, que pode ser de expansão (eventos representados em experiências não linguísticas) e projeção (eventos reapresentados em ambos os modos).

Texto e imagem ocupam um status igual ao se relacionarem por inteiro, ou seja, "uma imagem inteira está relacionada com o texto inteiro"10 (MARTINEC \& SALWAY, 2005, p.343). A relação status de igualdade pode ser subdivida em independente e complementar. Na primeira, as informações expressas em cada modo se realizam paralelamente e um não modifica o outro. $\mathrm{Na}$ segunda, texto e imagem modificam-se mutualmente e passam a formar um sintagma maior. Se, por outro lado, apenas um modo modifica o outro, texto e imagem ocupam um status desigual, no qual

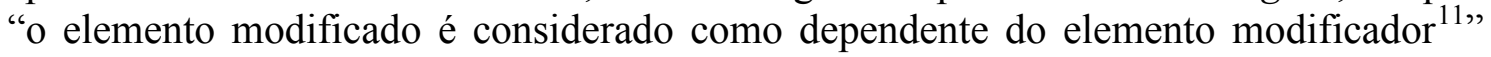
(id. ibidem). Neste caso, a imagem será o elemento subordinado quando ela estiver inteiramente relacionada a apenas uma parte do texto, da mesma forma que o texto estará subordinado à imagem quando estiver relacionado à apenas parte desta imagem.

O sistema desenvolvido por Martinec e Salway, portanto, consiste em ferramenta adequada para o estudo que propomos uma vez que estaremos analisando informações em ambos os modos (texto verbal e imagem) e a identificação da relação entre estes dois modos semióticos poderá contribuir para o diagnóstico do grau de importância atribuído àquelas informações ao compararmos ao que é requisitado como compreensão leitora e, especialmente, à promoção do letramento visual dos leitores/usuários das atividades analisadas.

\section{LETRAMENTO VISUAL: É PRECISO LER A IMAGEM}

As novas formas de interação e comunicação proporcionadas pelos avanços tecnológicos e, consequentemente, pelas mudanças sociais que passam a ser imprescindíveis para nos adequarmos à Era Digital, geram demandas por novos letramentos, que, no âmbito da linguagem, vão além das habilidades de ler e escrever e passam a (re)incluir processos de produção de sentidos por muito tempo atrelados à

\footnotetext{
${ }^{9}$ Neste estudo, não iremos tratar da relação lógico-semântica.

${ }^{10}$ When the relative image-text status is equal, a whole image is related to a whole text.

${ }^{11}$ The modifying element is considered to be dependent on the modified one."
} 
regência exclusiva do texto verbal. Conforme Goldstein (2008, p.3), "graças à tecnologia, vivemos em um mundo no qual imagens e informações visuais dominam nossas vidas diárias cada vez mais" ${ }^{12}$, nos mais diferentes contextos sociais e culturais ${ }^{13}$.

O letramento visual insere-se no conjunto de novos letramentos ora apresentados diante da necessidade de devolvermos à imagem o papel de produzir sentidos em eventos comunicativos, assim como o texto verbal. Em uma definição mais ampla, o letramento visual pode ser entendido como "um grupo de competências que permite que os seres humanos possam discriminar e interpretar ações, objetos e/ou símbolos visuais, naturais ou construídos, que eles encontram no meio ambiente ${ }^{14 ",}$ (ERIC, apud STOKES, 2002, p.12), ou, simplesmente a capacidade de ler, entender e utilizar informações visuais para a comunicação ${ }^{15}$. Em outras palavras, da mesma forma que o letramento digital implica a capacidade dos usuários de utilizar as tecnologias digitais de maneira eficaz, o letramento visual está diretamente relacionado ao entendimento da informação visual não apenas como um adorno da informação verbal, mas como um elemento semiótico que agrega sentido ao texto.

Segundo Kress (1998), é certo que o aspecto visual está presente no texto eletrônico, seja no formato da fonte (tipo, tamanho, cor), e/ou no layout, por exemplo, e que as tecnologias contemporâneas de produção e edição de texto têm facilitado a combinação destes e de outros modos de representação (por exemplo imagem - estática ou em movimento -, sons e texto verbal); mas é também correto afirmar que a integração de tais elementos depende de um processo que é tanto "um conjunto de fatores sociais, políticos, econômicos e culturais, quanto de desenvolvimentos representacionais / comunicacionais e tecnológicos" $"$ (id. Ibidem, p.54). Ao defender a interação entre imagem e texto, Kress chama a atenção para o perigo de que esta interação seja entendida erroneamente como 'visualização', na qual "[...] língua [texto escrito] e imagem 'estão fazendo a mesma coisa' [...] sendo apenas uma questão de tradução [...] de um modo semiótico para outro." ${ }^{\prime 7}$ (id. Ibidem, p.66). Neste caso, ao invés de um letramento visual que habilitaria o usuário a estabelecer as conexões necessárias entre os modos de informação, estaríamos diante de um processo tradutório de um modo para o outro.

Em relação aos ambientes de aprendizagem mediados por tecnologias computacionais e pelas facilidades que estas trazem para a inserção de diferentes modos e recursos semióticos, Goldstein $(2008$, p.4) alerta para o fato de que "[...] estas imagens estão sendo usadas como suporte a textos escritos que continuam a proporcionar o principal foco de nossa atenção em sala de aula." ${ }^{11}$ Esta mesma premissa pode ser

\footnotetext{
12 "thanks to technology, we live in a world in which images and visual information increasingly dominate our daily lives"

${ }^{13}$ No envio de fotos e vídeos de eventos sociais e culturais transmitidos concomitante com a realização destes eventos; nos mapas de GPS que acompanham os viajantes, entre muitos outros.

14 "a group of competencies that allows humans to discriminate and interpret the visible action, objects, and/or symbols, natural or constructed, that they encounter in the environment"

${ }^{15}$ Compilação de diferentes definições apresentadas por Stokes, 2002.

16 “a conjunction of social, political, economic and cultural as much as of representational/communicational and technological developments"

17 " [...] language and image are 'doing the same thing' [...] it is a merely matter of translating between the two modes [...] from one semiotic mode to another."

18 "With the advent of new technologies, interactive multimedia environments in CALL [...]

PROGRAMMES incorporate animated and full-motion video as well as still images [...] these images are used as a support to written texts which continue to provide the main focus of our attention in class"
} 
válida tanto para ambientes presenciais, - a sala de aula, como para ambientes virtuais. Kress e Van Leeuwen (2006, p.17) complementam este alerta ao afirmarem que, em uma via contrária, enquanto jornais e revistas combinam vários recursos semióticos na criação de seus layouts, "a educação produz analfabetos ${ }^{19}$ por priorizar, gradativamente, ao longo das séries mais avançadas, as informações verbais ao invés de nos ensinar a produzir textos que combinem os diversos modos. Segundo Stokes (2002, p.13), "estudantes desenvolvem suas habilidades visuais através do uso, ${ }^{20}$ " neste caso, a promoção do letramento visual seria um dos papeis da educação e, para tanto, deveria oferecer oportunidades para o desenvolvimento dessas habilidades. Neste artigo, analisaremos atividades de leitura em língua inglesa em busca de indícios de desenvolvimento de letramento visual.

\section{LEITURA DE HIPERTEXTOS: BREVE INTRODUÇÃO}

Neste cenário de novos letramentos, a leitura tem atraído a atenção de pesquisadores e ultrapassado os limites do meio (impresso ou digital). Conceitos de leitura como decodificação cedem espaços para a leitura tida como um processo no qual a interação entre texto e leitor passa a ser fundamental para a produção de sentido (ABERSOLD, 1997), e a linearidade é colocada à prova para qualquer tipo de texto, sejam eles impressos ou digitais, inclusive para narrativas literárias ${ }^{21}$.

A amplitude a que os conceitos de leitura têm chegado, aliada ao surgimento de diferentes suportes textuais, dentre eles o hipertexto eletrônico, instiga pesquisadores na busca pela identificação de características, estratégias e técnicas que a diferencie em relação a estes suportes. Autores como Miall (1998) e Dillon (1996) posicionam-se contra a ideia de um suporte como divisor de águas entre a leitura linear, por exemplo, que seria de exclusividade de textos impressos, e a leitura não linear proporcionada por hipertextos que seria facilitada ao oferecer grandes quantidades de informação e deixar o leitor livre para traçar seus próprios caminhos de leitura.

Não negando o impacto do hipertexto na educação, Dillon (1996, p.39) se opõe à garantia de que "a exploração de grandes quantidades de informações leve à integração dos conhecimentos," argumentando ainda que o hipertexto, a despeito de suas características em relação ao armazenamento e manipulação de informações, não deixa de ser exatamente um meio de apresentação da informação (id. ibidem), o que, portanto, desmistifica o caráter facilitador atribuído à leitura de textos neste suporte, exceto no tocante à localização das informações. Acessar um capítulo de um livro, por exemplo, pode ser mais fácil a partir de um link disponível no índice da página eletrônica que o folhear das páginas desse mesmo livro em meio impresso.

De fato, pesquisas, tais como a de Oliveira (2008), Araújo (2008) e Foltz (1996, apud GOMES, 2010), apenas para citar algumas, na busca pelo mapeamento de estratégias de leitura aplicadas à leitura de textos em meio digital, têm constatado mais similaridades que diferenças em relação à leitura em meio impresso. Se por um lado a leitura para coautoria na qual o leitor pode contribuir com novos textos ${ }^{22}$ é de exclusividade da leitura online, relatos de uso das estratégias tais como skimming,

\footnotetext{
19 "education produces illiterates"

20 "Students develop their visual abilities through use."

${ }^{21}$ Por exemplo, As cidades invisíveis de Ítalo Calvino e O jogo da amarelinha de Julio Cortázar, nas quais

o leitor é livre para traçar seus próprios caminhos de leitura.

${ }^{22}$ Como no caso de blogs, redes sociais e wikis, por exemplo.
} 
scanning, predição, têm sido observados nas pesquisas realizadas pelos autores citados, sejam para leitura de textos impressos ou digitais.

Por outro lado, se há um consenso geral de que a leitura de hipertextos é diferente da leitura de textos impressos, como afirma Gomes (2010, p.101) mas não temos conhecimentos sobre leitura suficientes para definir tal diferenciação, como argumenta Miall (1998), podemos estar diante de um quadro no qual discutimos a leitura de textos que se diferenciam enquanto suporte apenas, não em suas características próprias. Isto se torna mais evidente quando voltamos o olhar para atividades de leitura e constatamos que, no geral, estas, definitivamente, não se diferenciam: o que é esperado de seus usuários é, na maioria das vezes, exatamente o mesmo, sejam eles leitores de textos impressos ou digitais.

\section{CONSIDERAC̣ÕES METODOLÓGICAS}

\subsection{Descrição do material investigado}

Com ampla repercussão mundial, o portal eletrônico www.bbc.co.uk pode ser considerado mais que um portal de notícias, uma vez que disponibiliza aos seus usuários os tipos variados de serviços incluindo cursos de línguas online com diferentes atividades, além de apoio pedagógico a professores oferecendo sugestões, worksheets e materiais diversos que podem ser baixados e utilizados nas aulas de idiomas de forma gratuita. No conjunto dos cursos disponibilizados, destacamos o BBC Learning English ${ }^{23}$ que oferece um cenário para aprendizagem da língua inglesa voltada para diferentes propósitos (negócios, turismo, esporte, etc.), por meio de atividades diversas que apresentam uma grande riqueza de material didático com diferentes modos e recursos semióticos, além de um ambiente de interação entre os seus usuários, inclusive entre estes e os criadores do site.

A série Beyond the Postcard faz parte desse cenário de aprendizagem, e nela são disponibilizadas trinta e seis atividades distribuídas em atividades de leitura, de compreensão de áudio e de vídeo (12 de cada tipo). Com relação às atividades de leitura, foco da análise apresentada, cinco trabalham a compreensão de textos, com perguntas do tipo verdadeiro ou falso; e sete apresentam questões de múltipla escolha para a aprendizagem de vocabulário. O conteúdo dos textos apresentados nessa série de atividades estão todos relacionados a aspectos culturais, históricos e econômicos de cidades da Inglaterra, país de origem do sítio eletrônico. Ainda que não haja a indicação explícita de um público alvo, identifica-se a exigência de uma proficiência em língua inglesa a partir de um nível intermediário.

Em relação aos aspectos visuais, o layout segue a padronização do site, com o menu geral em cores pastéis à margem esquerda comum à todas as atividades e à página principal da Série; e apenas na margem direita da página de apresentação, um menu específico de atividades, em cores vibrantes - azul e verde e fundo cinza. Além do layout padronizado, as páginas das atividades apresentam links para informações adicionais e para as respostas corretas; e um aspecto visual semelhante, com texto verbal e imagem sob um mesmo pano de fundo, diferenciando apenas em suas informações específicas ${ }^{24}$. Há um link para o vocabulário disponível somente para as

\footnotetext{
${ }^{23} \mathrm{http}: / / w w w . b b c . c o . u k /$ worldservice/learningenglish/

${ }^{24}$ Como o ponto vermelho que indica a localização da cidade no mapa da Inglaterra.
} 
atividades de compreensão leitora, objeto desta análise. Os elementos apresentados acima podem ser vistos na Figura 1.

Figura 1 - Elementos principais das atividades de leitura

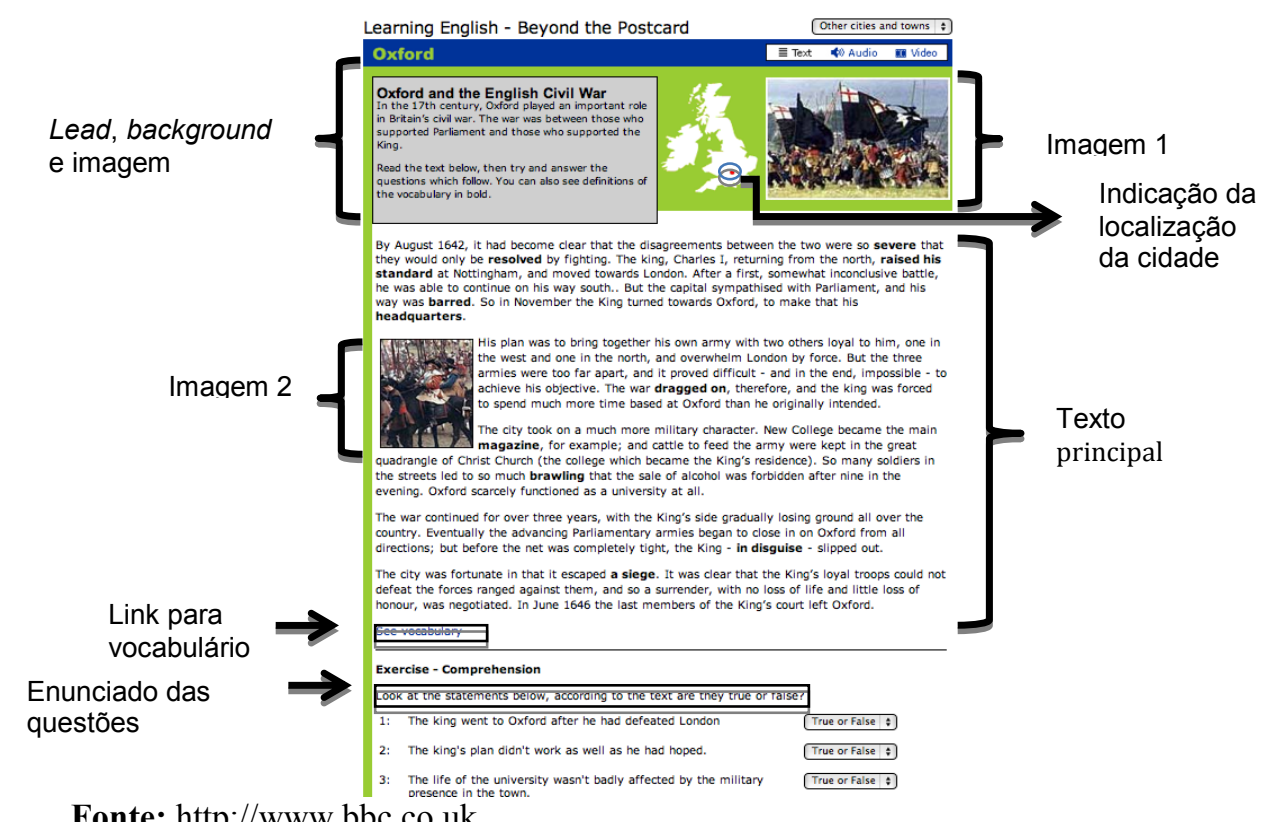

Fonte: http://www.bbc.co.uk

\subsection{Questões de pesquisa}

Com o propósito de uma melhor ordenação das ideias aqui propostas, estabelecemos algumas perguntas que irão nortear essa investigação. Concordamos com Bezemer \& Kress (2009, p.251) quando dizem que "contar imagens é um exercício problemático [...] já que elas não são compostas por entidades discretas, tais como as palavras, ${ }^{25,}$ e com Mayer $(2009$, p.3), ao afirmar que aprendizagem pode ser facilitada com uma explicação apresentada em palavras e imagens e não apenas em palavras. Mesmo diante da complexidade que a análise da imagem nos apresenta, mas acreditando no potencial de que esta, estando articulada ao texto, possa produzir significados para a leitura e compreensão de hipertextos em língua inglesa, interessanos descobrir: Quantas imagens estão inseridas nas atividades de leitura selecionadas? Quais relações podem ser estabelecidas entre texto e imagem nestas atividades? Quantas questões direcionam explicitamente as possíveis respostas ao papel das imagens e quantas poderiam ser respondidas a partir da leitura destas, ainda que não explicitamente direcionadas? Quais estratégias de leitura podem estar associadas para a obtenção das respostas e quantas podem ser associadas à análise das imagens?

\footnotetext{
25 "[...] counting images is a rather problematic exercise [...] since they are not made up of discrete entities such as words."
} 


\subsection{Algumas definições}

Diante da complexidade dos pressupostos teóricos que embasam as análises do material investigado, faz-se necessário breve destaque a alguns conceitos ${ }^{26}$ básicos. Consideramos a noção de texto multimodal adotada como de um conjunto de diferentes modos que, de forma integrada e articulada, se constitua em um objeto de significação e comunicação, cuja materialização dependerá de uma postura interativa por parte do leitor. Entretanto, para propósitos de análise, a palavra texto verbal será utilizada como referência à informação verbal, sendo que ao mencionarmos texto principal estaremos nos referindo ao corpo central do texto verbal, não sendo considerados o título, o subtítulo e o $l e a d^{27}$. Em relação à imagem, ainda que esta possa também ser concebida como todo o aspecto visual do texto, incluindo o texto escrito, as características tipográficas (como o estilo, a cor e o tamanho da fonte), além do background e layout da página, para o presente estudo, consideramos imagem apenas como fotografia, desenho, pintura, diagrama ou mapa, fazendo apenas uma breve distinção entre fotografias e desenhos de acordo com o senso de real e imaginário invocados por ambos, respectivamente, segundo Bezemer e Kress (2009, p.254). Finalmente, por estratégia de leitura, consideramos como o método pelo qual a resposta correta pode ser obtida (UNSWORTH at all, 2004).

\subsection{Procedimentos de análise}

Partindo dos conceitos acima expostos e adotando uma abordagem qualiquantitativa aos dados, estabelecemos como procedimentos de análise a seleção das atividades de acordo com o propósito das questões. Foram selecionadas cinco das dozes atividades da Série por estarem relacionadas à compreensão leitora dos textos e não ao aprendizado de vocabulário; o diagnóstico do valor da informação de acordo com a Gramática do Design Visual de Kress e Van Leeuwen (2006) e da relação de status entre texto e imagem segundo Martinec e Salway (2005); a verificação das instruções nos enunciados das questões em busca de um direcionamento ao letramento visual; e a identificação das estratégias de leitura necessárias para a obtenção das respostas consideradas corretas. As estratégias, elencadas a seguir, foram derivadas e adaptadas do estudo realizado por Unsworth et all (2004): 1. Ler o texto principal; 2. Ler o lead; 3. Ler o lead e a(s) imagem(ns); 4. Ler a(s) imagem(ns); e 5. Ler título e imagem.

\section{APRESENTAÇÃO E DISCUSSÃO dOS RESULTADOS}

Embora não faça parte de nossos objetivos, antes de nos determos na análise da relação texto-imagem e nas questões propostas nas atividades de leitura selecionadas, convém ressaltar a identificação de outros recursos semióticos que compõem o aspecto visual destas atividades. Nos referimos à tipografia e a utilização de cores para sinalizar informações julgadas relevantes para a compreensão dos textos. Em relação à tipografia,

\footnotetext{
${ }^{26}$ Cujas definições serão apresentadas como uma compilação das principais teorias que os discutem.

${ }^{27}$ Este último, por sua vez, é um termo do jornalismo que se refere à primeira parte de uma notícia (neste caso, o texto) e que tem como objetivo proporcionar ao leitor informações básicas sobre o assunto a ser abordado, ou ainda a descrição de uma imagem, a fim de manter-lhe o interesse.
} 
além de tamanhos e cores diferentes nos títulos, de acordo suas funções no texto, palavras em negrito se destacam no corpo do texto principal para indicar que suas definições podem ser acessadas no link (em fonte azul) que o segue, sendo que em uma das cinco unidades (Oxford) essa informação é apresentada, também, em texto verbal. Além da cor azul da fonte dos links, que se diferencia da fonte preta do texto, há um ponto vermelho sobre o fundo branco do mapa da Inglaterra, como já mostrado anteriormente, que indica a localização da cidade de que trata o texto. Essa informação não é apresentada no texto verbal. Nestes casos, enquanto a cor preta da fonte agrupa o texto como um todo, as cores azul e vermelho distinguem e sinalizam informações relevantes e, portanto, cumprem as metafunções da linguagem.

\subsection{Quantificando e caracterizando as imagens}

Uma análise geral das doze atividades de leitura da Série Beyond the Postcard revelou um perfil visual (considerando apenas as imagens inseridas nos textos) composto por 27 imagens distribuídas conforme mostra a Tabela 1.

Tabela 1 - Perfil das atividades da Série Beyond the Postcard

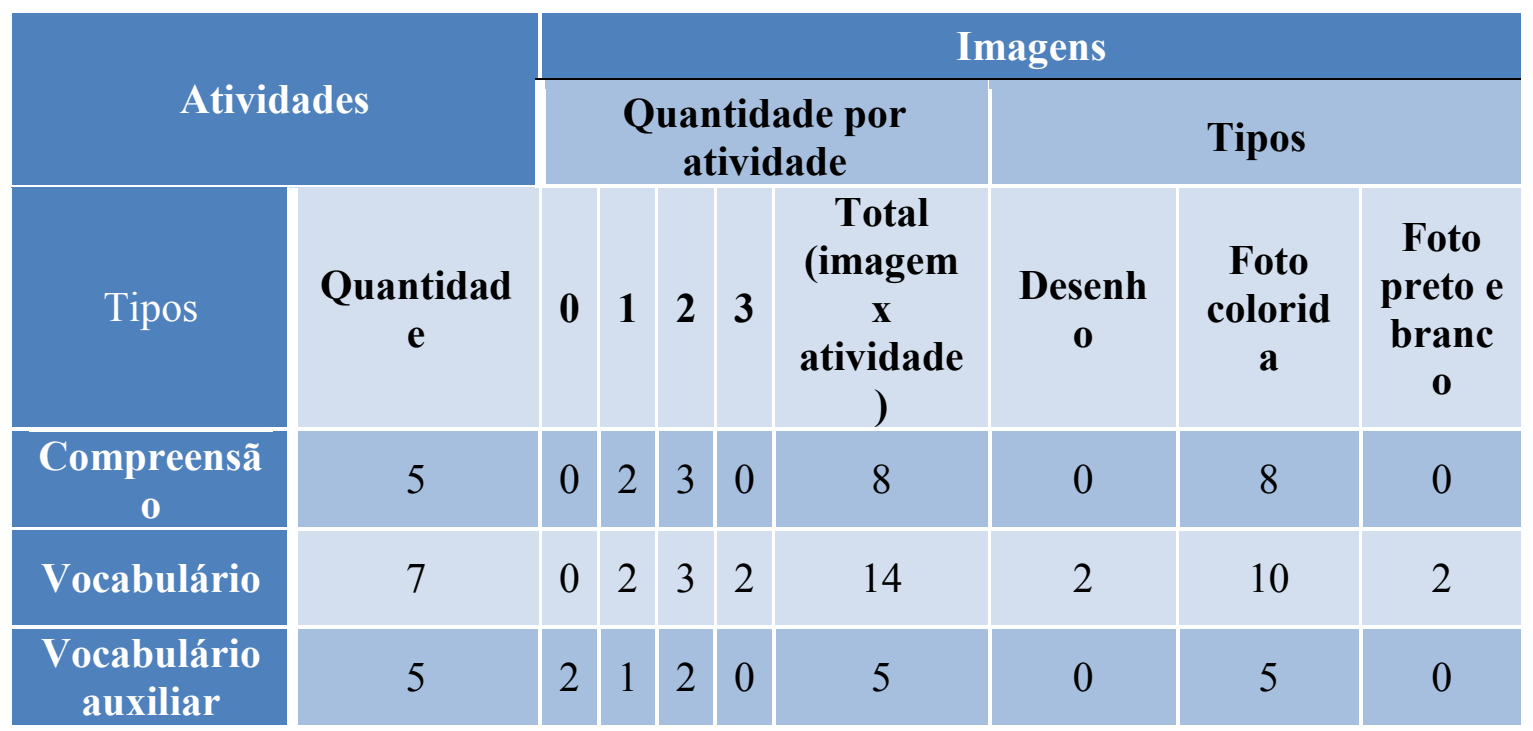

A Tabela 1 mostra que nas cinco atividades de Compreensão, além da imagem do mapa da Inglaterra sobre um fundo verde, comum a todos os textos, ${ }^{28}$ em todas as atividades analisadas há, pelo menos, 01 (uma) imagem próxima ao lead ${ }^{29}$, e em três há mais uma imagem inserida no corpo do texto principal, ou seja, duas atividades com 01 imagem, três com 02 e nenhuma com 0 ou 03 imagens, totalizando 08 imagens; ou, ainda, 1,6 imagem por atividade (8/5). Mesmo com o texto verbal ocupando a maior parte da página, esta proporção indica o potencial da imagem em produzir significados e, que, portanto, pode ser explorado para facilitar a compreensão leitora. Estes resultados respondem à primeira pergunta deste estudo: Quantas imagens estão inseridas nas atividades de leitura selecionadas?

\footnotetext{
${ }^{28}$ Como já explicado anteriormente.

${ }^{29}$ Para facilitar a análise, e por conveniência, doravante chamaremos esta parte do texto de cabeçalho.
} 
Indo um pouco além da pergunta, entretanto, ao compararmos a quantidade de imagens nas atividades de Compreensão e Vocabulário, observamos que há uma quantidade maior nas atividades de Vocabulário em relação àquelas de Compreensão, tanto em termos quantitativos, 8 e 14, quanto em termos proporcionais que é de 1,6 $(8 / 5)$ e $2,0(14 / 7)$ por atividade, respectivamente ${ }^{30}$. De qualquer maneira, mesmo tendo como foco apenas as atividades de compreensão leitora, chama-nos a atenção a frequência geral da incidência de imagens em praticamente todas as atividades, inclusive naquelas de consulta ao vocabulário (na Tabela 1 a chamamos de Vocabulário auxiliar) que, por se tratarem de definições, poderia ser esperado que fossem apresentadas exclusivamente em textos verbais, tendência confirmada pela ocorrência de duas, das cinco atividades deste tipo, nas quais não há nenhuma imagem inserida. $\mathrm{E}$, ainda, uma maior recorrência de imagens fotográficas em relação aos desenhos, indicando uma possível invocação daquilo que é real e não do que é parte do mundo imaginário, conforme explicado por Bezemer \& Kress (2009, p.254), aspecto que pode ser mais bem diagnosticado por meio da análise da modalidade nas fotografias ${ }^{31}$ segundo as ideias de Kress \& Van Leeuwen (2006, p.154) e Van Leeuwen (2005, p.160).

\subsection{Explorando relações entre texto-imagem}

A primeira relação texto-imagem que propomos estabelecer diz respeito ao valor de informação na realização da metafunção composicional da Gramática do Design Visual de Kress e Van Leeuwen (2006). Considerando a estruturação do texto verbal em duas partes que faz distinguir as duas áreas principais do texto (o cabeçalho composto pelo lead, mapa e imagem 1; e o texto principal), detalhadas na Figura 1, entendemos que o posicionamento na margem superior, a informação ideal, faz com que o cabeçalho cumpra o papel de apresentar o texto principal (informação real), convidando o leitor a descobrir mais sobre o assunto a ser tratado. Em outras palavras, enquanto lead, mapa e imagem 1 apresentam o assunto de forma sucinta, será no texto principal que o leitor irá descobrir informações detalhadas a respeito do assunto apresentado, e que irão aprofundar seus conhecimentos e torná-lo apto a responder corretamente $^{32}$ as questões propostas. Essa mesma relação pode ser observada quando consideramos o texto principal como as informações generalizadas e as questões propostas (localizadas logo abaixo do texto principal) como informações concretas, ou seja, aquelas que realmente devem interessar ao leitor.

O posicionamento dos elementos no cabeçalho indica uma combinação tríptica formada por três blocos de informação organizados horizontalmente no eixo margemcentro-margem, onde, o mapa situado entre o lead e a imagem 1 atua como elemento mediador entre o dado e o novo, possivelmente indicando que as informações apresentadas no lead e na imagem tratam-se da cidade inglesa escolhida pelo leitor e cuja localização é indicada no mapa do país. Nesse bloco de informação, o texto verbal (lead) apresenta-se na margem esquerda, considerada a informação dada com a qual se pressupõe que o leitor já esteja familiarizado, enquanto a imagem 1, localizada à

\footnotetext{
${ }^{30}$ Em relação às atividades de vocabulário, cabe outra investigação que indique a relação entre as imagens inseridas naquelas atividades e a promoção da aprendizagem de vocabulário, não objeto deste estudo.

${ }^{31}$ Aspecto que não será discutido neste trabalho, a despeito de sua pertinência.

${ }^{32}$ De acordo com o apresentado no site.
} 
margem direita, assume o papel de informação nova, merecendo especial atenção. Esta mesma relação se repete em duas das três atividades que contêm uma imagem adicional inserida no corpo do texto principal, porém, desta vez, de forma inversa com a imagem (neste caso, a imagem 2) sendo colocada à esquerda e o texto verbal à direita. Tal ocorrência pode ser explicada quando se entende que as informações trazidas na segunda imagem já tenham sido apresentadas ao leitor antes, seja em texto verbal (como na Figura 1) ou não-verbal, aspecto mostrado a Figura 2 na qual temos duas imagens do mesmo castelo, o que não significa que estão dizendo a mesma coisa ${ }^{33}$, apenas reafirmam as ideias de Kress e Van Leeweun (2006) de que "[...] se a margem esquerda contém uma imagem e a direita um texto verbal, a imagem é apresentada como Dado, um ponto de partida bem estabelecido para o texto, e o texto contém o Novo. Se a página esquerda tem um texto e a direita uma imagem, o texto contém o Dado e a imagem o Novo." 34

Figura 2 - Metafunção composicional: valor da informação

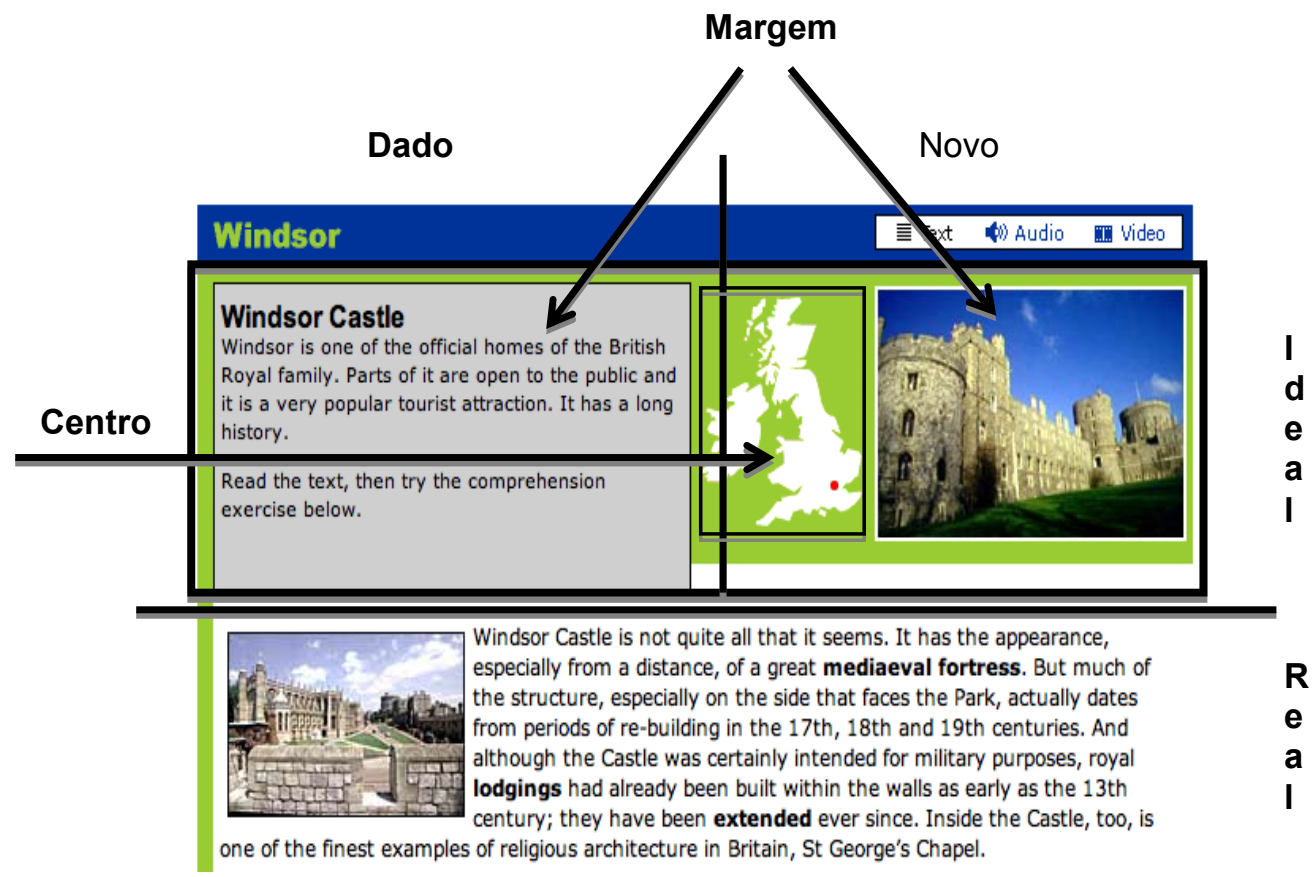

Fonte: http://www.bbc.co.uk

No exemplo analisado, o lead traz informações a respeito do Castelo de Windsor que são complementadas com a imagem 1. Em uma leitura linear, essas informações proporcionarão ao leitor o conhecimento prévio a respeito da segunda imagem, necessitando, portanto, das informações adicionais que serão apresentadas no texto verbal que a segue. Em relação à unidade Edinburgh na qual a imagem 2 é apresentada como informação nova ao texto que a antecede, percebe-se que neste há o direcionamento para a leitura daquela, seguindo a mesma interpretação da relação estabelecida entre lead-imagem 1.

\footnotetext{
${ }^{33}$ Esta questão pode ser explicada através da análise da metafunção interpessoal/interativa.

34 [...]If the left contains a picture and the right is verbal text, the picture is presented as Given, as a wellestablished point of departure for the text, and the text contains the New. If the left page has text and the right page a picture, the text contains the Given, and the picture the New.
} 
Se entendermos a ideia de que informação nova pressupõe certa dependência da informação dada (antiga) e considerarmos a maior recorrência da apresentação da imagem como informação nova nas atividades analisadas, podemos supor, então, que, neste caso, houve a predominância da relação de subordinação da imagem ao texto. Suposição que pôde ser avaliada ao aplicarmos as categorias de status propostas por Martinec e Salway (2005).

Do mesmo modo que os autores, estabelecemos o parágrafo e a sentença como unidades máxima e mínima para nos referirmos ao texto inteiro ${ }^{35}$ (id. Ibidem, p.347). No nível do parágrafo, ${ }^{36}$ entendemos todas as oito imagens analisadas como subordinadas ao texto uma vez que não mostram tudo o que o texto relata, ou seja, se relacionam apenas a parte destes textos. Ao nível de sentença, identificamos um único caso no qual texto e imagem se relacionam por inteiro e se complementam, formando um sintagma maior; e nenhum caso no qual o texto se relacione apenas com parte da imagem, estando subordinada à esta. Sendo assim, mesmo ao nível da sentença, confirma-se o status de subordinação da imagem em relação ao texto. No Quadro 1, apresentamos um exemplo de cada uma das duas situações identificadas.

Quadro 1 - Relação de status entre texto e imagem, a nível de sentença

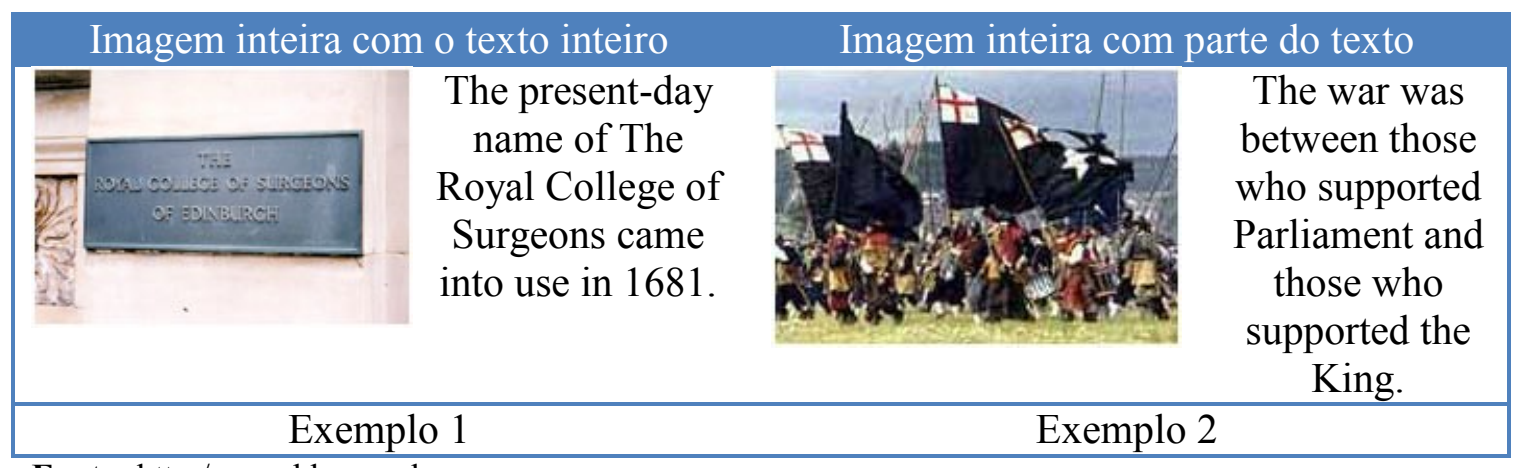

Fonte: http:/www.bbc.co.uk

No exemplo 1, entendemos que, ainda que texto e imagem se refiram ao mesmo participante (a instituição), ambos se completam na medida em que acrescentam informações a respeito desse participante (que tipo de instituição e qual o nome atual desta). No exemplo 2, o texto menciona os dois lados da guerra, que seriam os dois participantes, mas, a imagem mostra apenas um deles.

A relação de desigualdade entre texto e imagem que a coloca subordinada ao texto, mantendo-o coesivo mesmo que esta fosse retirada por completo, "não significa que as imagens não acrescentem significados ao texto - ao contrário. Elas tornam visíveis aspectos de um mundo sobre o qual o texto se refere, mas não necessariamente detalha $^{37 "}$ (BEZEMER \& KRESS, 2009, p.253). Por exemplo, na Figura 2, os textos verbais próximos às imagens (lead e primeiro parágrafo do texto principal) apresentam informações relevantes a respeito do Castelo de Windsor, mas é nas imagens que detalhes, tais como aspectos físicos do castelo, são revelados ao leitor. O mesmo pode

\footnotetext{
${ }^{35}$ Os autores consideraram, ainda, outras unidades, como a palavra, por exemplo.

${ }^{36} \mathrm{O}$ mais próximo da imagem para que a relação dado/novo possa ser mantida.

37 "This does not mean that the images do not add meaning to the text - on the contrary. They make visible those aspects of a world to which the writing refers but which the writing does not necessarily detail."
} 
ser dito da unidade York cujo assunto do lead é sobre os vikings e a imagem traz a suposta $^{38}$ caracterização de um.

\subsection{Promovendo o letramento visual através das questões de compreensão}

O mesmo status da imagem de estar subordinada ao texto é ressaltado nos enunciados das questões e nos textos que compõem os leads. Nos leads das doze unidades há a orientação para a leitura dos textos para responder às questões propostas, sendo que em uma das unidades (Oxford) há, ainda, a indicação de que as definições das palavras em negritos podem ser consultadas, e em outra unidade (Belfast), além da orientação, o texto do lead é também a apresentação do texto principal, ou seja, constitui um duplo direcionamento para o texto verbal (Quadro 2, Exemplos 1 e 2, respectivamente). Quanto aos enunciados das questões, nas cinco unidades analisadas, eles reafirmam a orientação apresentada nos leads ao instruir os leitores a responderem as questões de acordo com o texto, como também pode ser visto na Figura 1 e transcrito abaixo:

\section{Look at the statements below, according to the text are they true or false?}

Quadro 2 - Exemplos de leads

\section{Exemplo 1: Oxford}

Oxford and the English Civil War

In the 17th century, Oxford played an important role in Britain's civil war. The war was between those who supported Parliament and those who supported the King.

Read the text below, then try and answer the questions which follow. You can also see definitions of the vocabulary in bold.

\section{Exemplo 2: Belfast}

Industry in Belfast

Belfast is the capital of Northern Ireland and is an industrial city. This text looks at some of the features of that industry including shipbuilding and linen production.

Read the text, then try the comprehension exercise below.

Fonte: http://www.bbc.co.uk

Quando observado o teor das perguntas ${ }^{39}$ e suas possíveis relações com as imagens, considerando a palavra como unidade mínima e excluindo referências, das 25 perguntas (05 para cada unidade), apenas 8 mantêm uma relação com a imagem, numa proporção de 0,32 , e destas, duas teriam suas respostas condicionadas à leitura do texto verbal, e por isso não estão computadas na Tabela 2, que, além da relação pergunta/imagem, apresenta a quantidade de respostas que evidenciam o potencial da imagem na produção de sentido ${ }^{40}$.

\footnotetext{
${ }^{38}$ Suposta porque a figura que o representa não o caracteriza como tal.

${ }^{39}$ Exemplos das perguntas podem ser vistos nos Quadros 3 e 4.

${ }^{40}$ Ainda que este possa não ser o esperado pelos produtores da atividade, quando considerada como resposta correta, conforme veremos a seguir.
} 
Tabela 2 - Relação entre perguntas/imagens/respostas

\begin{tabular}{|c|c|c|c|c|c|c|}
\hline Relação & $\begin{array}{c}\text { Edinbur } \\
\text { gh }\end{array}$ & Belfast & York & Oxford & Windsor & Total \\
\hline Pergunta/imagem & 2 & 2 & 0 & 3 & 1 & 8 \\
\hline Imagem/resposta & 2 & 1 & 0 & 1 & 1 & 5 \\
\hline
\end{tabular}

Além das duas questões cujas respostas estariam condicionadas à leitura do texto verbal, em mais três questões a leitura da imagem poderia levar o leitor a uma resposta diferente da que é apresentada como correta ${ }^{41}$. Essas relações podem ser observadas no Quadro 3, Ex. 1 e Ex. 2, respectivamente.

Quadro 3 - Exemplos de perguntas com alguma relação com a imagem

\begin{tabular}{|l|l|l|}
\hline \multicolumn{1}{|c|}{ Pergunta } & \multicolumn{1}{c|}{\begin{tabular}{c}
\multicolumn{1}{c}{ Resposta ${ }^{42}$} \\
Ox. 1: 1. The king went to \\
Oxford after he had defeated \\
London
\end{tabular}} & $\begin{array}{l}\text { 1. False. The king's way } \\
\text { was barred. He didn't get } \\
\text { to London. }\end{array}$ \\
\hline $\begin{array}{l}\text { Ex. 2: 4. The king escaped } \\
\text { from Oxford by hiding his } \\
\text { identity }\end{array}$ & $\begin{array}{l}\text { 4. True. He escaped in } \\
\text { disguise. }\end{array}$ \\
\hline
\end{tabular}

Fonte: http://www.bbc.co.uk

Com esta análise, condicionando a promoção do letramento visual aos enunciados das questões, constatamos que em nenhuma das cinco atividades há qualquer indicação para a leitura das imagens. Da mesma forma, nenhuma das perguntas propostas direcionam explicitamente as possíveis respostas ao papel das imagens, ainda que em três das vinte e cinco perguntas a resposta correta possa ser alcançada integrando enunciado e imagem, sem a necessidade da leitura do texto principal, como no exemplo do Quadro 4.

Quadro 4 - Exemplo de relação imagem/resposta

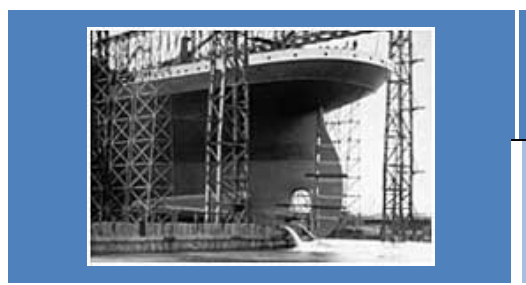

Pergunta:

1. Belfast's location was useful for shipbuilding.

Resposta:

1. True. Belfast's location 'helped' shipbuilding.

Fonte: http://www.bbc.co.uk

\footnotetext{
${ }^{41}$ Estes caminhos de leitura serão explicados no tópico seguinte.

${ }^{42}$ Respostas transcritas diretamente do site.
} 


\subsection{Identificando as estratégias e suas relações com as imagens}

Ao selecionarmos as estratégias que poderiam estar associadas à obtenção das respostas consideradas corretas pelos criadores das atividades, não contávamos com a vinculação daquelas respostas à leitura do texto principal e, por isso, a incluímos na lista. Entretanto, os resultados mostram que não somente a leitura do texto principal é a estratégia mais indicada para o propósito das atividades como, também, deva ser uma leitura linear, pois as respostas esperadas encontram-se exatamente na mesma sequência das perguntas. Portanto, o argumento de que a leitura de hipertextos é uma leitura não linear torna-se inaplicável e apenas ressalta o que dissemos anteriormente de que, até então, o suporte esteja sendo o principal fator de diferenciação entre textos impressos e textos digitais.

Ainda assim, a despeito da orientação de que as respostas deveriam ser obtidas a partir da leitura do texto principal, buscamos identificar outras estratégias que poderiam ser utilizadas, mesmo que estas não tenham sido indicadas nas atividades. Os dados que iremos apresentar, no entanto, são dados não testados e ao obtê-los desconsideramos a possibilidade de que, ao aplicar tais estratégias, o leitor possa chegar a uma resposta diferente da apresentada como correta.

Tabela 3 - Estratégias de leitura

\begin{tabular}{|c|c|c|c|c|}
$\begin{array}{l}\text { 1. Ler o texto } \\
\text { principal }\end{array}$ & 2. Ler o lead & $\begin{array}{l}\text { 3. Ler o lead e } \\
\text { a(s) imagem(s) }\end{array}$ & $\begin{array}{l}\text { 4. Ler a(s) } \\
\text { imagem(ns) }\end{array}$ & $\begin{array}{l}\text { 5. Ler título e } \\
\text { imagem }\end{array}$ \\
\hline 25 & 3 & 4 & 1 & 2 \\
\hline
\end{tabular}

Ressaltando que mais de uma estratégia possa ser utilizada para responder as questões propostas, observamos que, apesar de todas as perguntas estarem atreladas à leitura do texto principal, outros elementos textuais, sejam eles verbais ou visuais, também participam da produção do sentido e, mais importante ainda para nossa análise, constatamos o papel da imagem nessa produção, mesmo não tendo sido observada nenhuma oportunidade explícita para o desenvolvimento das habilidades visuais do leitores dos textos multimodais analisados. Os resultados apresentados na Tabela 3, portanto, responde à pergunta deste estudo sobre as estratégias de leitura e quantas podem ser associadas à análise das imagens.

\section{CONSIDERAÇÕES FINAIS}

$\mathrm{Na}$ análise apresentada neste artigo, mostramos que a produção de materiais didáticos, especificadamente para o âmbito dessa pesquisa as atividades de leitura em sítio eletrônico, tem acompanhado os avanços nas Tecnologias de Comunicação e Informação no que diz respeito às composições multimodais que oferecem ao leitor uma variedade de informações disponíveis em diferentes modos e recursos semióticos. Nas atividades analisadas, observamos, por exemplo, cores e tamanhos de fontes diferentes para sinalizar aspectos relevantes do texto e indicar possíveis caminhos de leitura, a disposição dos elementos compondo um aspecto visual harmônico e informações apresentadas em diferentes modos semióticos (texto e imagem, neste caso). Entretanto, constatamos que o mesmo não pode ser dito a respeito dos materiais didáticos online 
quando consideramos os enunciados destas atividades que não apenas direcionam e controlam o leitor, guiando-o para uma leitura linear, de parágrafo a parágrafo, como também, e mais importante, não promovem o letramento visual ao vincularem a obtenção da resposta considerada correta à leitura do texto verbal, mantendo-o como modo dominante, cujos exemplos foram mostrados na Figura 1 (p.9) e no Quadro 2 (p.17).

Diagnosticamos o papel da imagem, nestas atividades, com dados estatísticos que nos mostraram uma média de 1,6 imagem por atividade, o que significa que mesmo o texto verbal ocupando um maior espaço na página virtual, esta proporção pode indicar o potencial da imagem na construção do sentido do texto e de relações que podem ser estabelecidas entre estes dois modos.

Como categorias de análise destas relações, o valor de informação presente na metafunção composicional, de acordo com a GDV, mostrou-se aplicável para estudos desta natureza especialmente sob dois aspectos: na relação ideal/real, percebemos que lead e imagem foram mostrados como informações mais generalizadas a respeito do assunto tratado no texto principal e, mais relevante ainda, quando consideramos a disposição do texto principal e das questões propostas, entendemos que o texto principal é tido como informação generalizada, enquanto que o que é destacado nas perguntas/respostas é a informação concreta e, portanto, é o que o leitor precisa realmente saber. A relação dado/novo nos mostrou dois pontos um tanto quanto contraditórios, mas condizente com o que temos afirmado: considerando a relação lead e imagem, o primeiro seria a informação já familiar ao leitor que, de certa forma, apresentaria a segunda. Por um lado, entendemos que, nesse caso, a imagem, estaria subordinada ao texto verbal, mas, por outro lado, considerando que esta informação nova seria aquela para o qual o leitor deveria dar maior atenção, observamos que há divergência entre o papel da imagem, ressaltado nesta relação, e o que é considerado como informação importante, segundo a interpretação dos criadores das atividades através das questões propostas.

O sistema elaborado por Martinec \& Salway (2005) para diagnosticar o status da imagem em relação ao texto verbal mostrou-se aplicável ao reafirmar a tendência, nos textos didáticos, de um status de desigualdade que coloca a imagem como subordinada ao texto verbal, mas, por outro lado, ressalta que mesmo estando subordinada ao texto, a imagem acrescenta informações não apresentadas no texto verbal, devendo, portanto, ser "lida" também.

A regência do texto verbal também foi constatada nos enunciados e questões propostas nas atividades, quando constatamos o direcionamento para uma leitura linear e exclusivamente das informações verbais, fazendo com que a leitura do texto verbal tenha sido a mais indicada para encontrar a resposta esperada. Porém, também diagnosticamos a potencialidade de que outras estratégias que privilegiasse a leitura da imagem fossem utilizadas.

Finalmente, os resultados das análises da relação texto-imagem, confrontados aos enunciados e ao teor das questões propostas, comprovaram o que temos dito a respeito da divergência entre os materiais instrucionais e a multimodalidade nas atividades de leitura disponíveis em meio eletrônico. A despeito de toda a diversidade de modos e recursos semióticos nestas composições, os materiais instrucionais não promovem o uso integrado destes recursos, ou seja, não oferecem, pelo menos explicitamente, oportunidades para o desenvolvimento das habilidades visuais de seus leitores/usuários, cabendo a estes leitores a responsabilidade de ir além do que lhes é 
solicitado nas instruções destas atividades e, desta forma, encontrar caminhos que facilitem o processo de letramento visual. Caminhos que poderiam ser indicados através de uma metalinguagem própria e adequada a este gênero e suporte textual.

\section{REFERÊNCIAS}

ABERSOLD, J. A.; FIELD, H. L. From Reader to Reading Teaching: issues and strategies for second language classrooms. New York: Cambridge University Press, 1997.

ALMEIDA, D. B. L. DE (org). Perspectivas em Análise Visual: do fotojornalismo ao blog. João Pessoa: Editora da UFPB, 2008.

ARAÚJO, A. D. Leitura de textos eletrônicos: diagnosticando estratégias de compreensão. In:

TOMITCH, L. M. B. (Org.). Aspectos cognitivos e instrucionais da leitura. Bauru, SP: EDUSC, 2008, p. 193-212.

BARTHES, R. Image, Music, Text. New York: Hill and Wang, 1997.

BEZEMER, Jeff; KRESS, G. Visualizing English: a social semiotic history of a school subject. Visual Communication. Vol. 8(3), 247-262, 2009.

DILON, A. Myths, misconceptions, and alternative perspective on information usage and the eletronic médium. In ROUET, J. F., LEVONEN, J. J., DILLON \& SPIRO R. (Eds). Hypertext and Cognition. Mahwah, n. J.: Lawrence Erlbaum, 1996, p. 25-42.

GOMES, L. F. Hipertextos multimodais - leitura e escrita na era digital. Jundiaí: Paco Editora, 2010.

GOLDSTEIN, B. Working with Images: a resource book for the language classroom. Cambridge: Cambridge University Press, 2008.

KRESS, G. Visual and verbal modes of representation in electronically mediated communication. In: SNYDER, I. (ed). Page to Screen: talking literacy into electronic era. New York: Roulledge, 1998, p. 53-79.

KRESS, G. \& VAN LEEUWEN, T. Reading Images. London: Routledge, 2006.

MARTINEC, R. \& SALWAY, A. A system for image-text relation in new (and old) media. Visual Communication, 4(3): p. 337-71, 2005.

MAYER, R. E. Multimedia Learning. USA: Cambridge University Press, 2009.

OLIVEIRA, S. Hipertextos e aspectos afetivos. In: TOMITCH, L. M. B. (Org.). Aspectos cognitivos e instrucionais da leitura. Bauru, SP: EDUSC, 2008. 
STOKES, S. Visual literacy in teaching and learning: a Literature Perspective. Eletronic Journal for the Integration of Technology in Education, vol. 1, n.1, p. 10-19, 2002.

MACHIN, D. Introduction to multimodal analysis. London: Hodder Arnold, 2007.

MIALL, D. S. Hypertextual reading: what's the difference? Disponível em < http://www.ualberta.ca/ dmiall/reading/hypdiff.htm > Acesso em: 13 jun 13.

UNSWORTH, L. Multiliteracies and metalanguage: Describing image/text relations as a resource for negotiating multimodal texts. In: COIRO J. et al (eds.). Handbook of research on new literacies. New York: 2009, p. 377-405.

UNSWORTH, L.; THOMAS, ANGELA; BUSH, R. The role of images and image-text relations in group "Basic Skills Tests" of literacy for children in the primary school years. Australia: Australian Journal of Language and Literacy, Feb 1, 2004.

VAN LEEUWEN, T. Conjunctive structure in documentary film and television. Continuum 5 (1), 1991, p. 76-114.

. Typographic meaning. Visual Communication, 4: p. 137-52, 2005.

. Multimodality. In. SIMPSON, J. (Editor). The Routledege Handbook of Applied Linguistics. London and New York: Routledge, 2011, p. 668-682.

Recebido em: 18 de fevereiro de 2014.

Aceito em: 14 de maio de 2014. 